\title{
WIND-TUNNEL EXPERIMENTS AND CFD SIMULATIONS TO STUDY THE INCREASE IN SHIP RESISTANCE COMPONENTS DUE TO ROUGHNESS
}

\author{
MUHAMMAD LUQMAN HAKIM ${ }^{1}$, NIKO MAQBULYANI ${ }^{1}$, BAGUS NUGROHO$^{2}$, I KETUT \\ SUASTIKA $^{1}$ AND I KETUT ARIA PRIA UTAMA*1
}

${ }^{1}$ Department of Naval Architecture, Faculty of Marine Technology, Institut Teknologi Sepuluh Nopember, Surabaya, 60111, Indonesia. ${ }^{2}$ Department of Mechanical Engineering, School of Engineering, The University of Melbourne, Victoria, 3010, Australia.

*Corresponding author: kutama@na.its.ac.id

Submitted final draft: 23 April $2020 \quad$ Accepted: 25 June 2020

http://doi.org/10.46754/jssm.2021.04.012

\begin{abstract}
This is a study on the effect of hull roughness on ship resistance components (especially full viscous resistance), which is tested using wind-tunnel experiments and Computational Fluid Dynamics (CFD) simulations. With the wind-tunnel experiment, a full viscous resistance analysis can be carried out to further explore changes in the friction and pressure resistance only without the wave resistance. In the experiments, the roughness model used sandpaper with an average roughness height $\left(k_{a}\right)=162 \mu \mathrm{m}$, that then it was predicted equal with $k_{\mathrm{s}}=1475 \mu \mathrm{m}$. In the CFD simulations, the roughness parameter was represented by an equivalent sand grain roughness height $\left(k_{s}\right)$, and this was varied by several levels. The results indicated that there was a significant increase in $\Delta C_{T}$ (up to $73.7 \%$ ) and $\Delta C_{F}$ (up to $106.96 \%$ ), but only a slight increase in $\Delta C P$ (up to $10.57 \%$ ). The trend of the increase in resistance due to $k_{s}$ and Reynolds numbers were also discussed. The parameter $k_{s}$ were very influential on $\Delta C_{F}$, but had only a slight effect on $\Delta C P$. With the significant results about the increase in ship resistance due to the roughness, both the friction and the pressure resistance component will lead to an increase in fuel consumption on a ship then it will increase levels of carbon emissions in the air.
\end{abstract}

Keywords: Ship resistance, wind-tunnel experiment, computational fluid dynamics, roughness, biofouling.

$\begin{array}{ll}\text { Abbreviations: } \\ \text { LOA } & : \text { Length over All } \\ \text { LPP } & : \text { Length between Perpendicular } \\ \text { LWL } & : \text { Length on Waterline } \\ B & : \text { Breadth } \\ T & : \text { Draft } \\ \nabla & : \text { Volume Displacement } \\ W S A & : \text { Wetted Surface Area } \\ C_{B} & : \text { Coefficient Block } \\ C_{T} & : \text { Coefficient of total resistance } \\ C_{F} & : \text { Coefficient of friction resistance } \\ C_{R} & : \text { Coefficient of residuary resistance } \\ C_{P} & : \text { Coefficient of pressure resistance } \\ C_{W} & : \text { Coefficient of wave resistance } \\ k_{s} & : \text { Equivalent sand-grain roughness height }\end{array}$




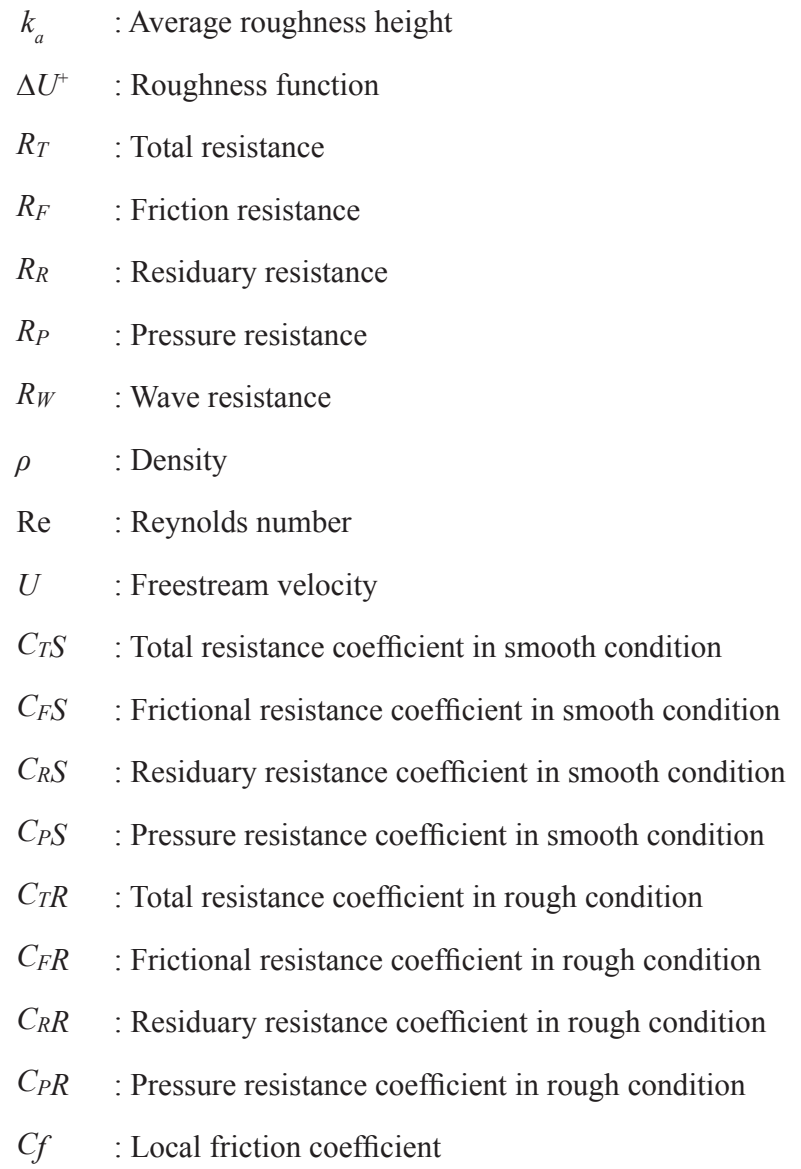

\section{Introduction}

Respecting the issue of global warming and climate change, the quality and the quantity of gas emissions on ships has become a distinct concern by the International Maritime Organization (IMO). The trade activities throughout the world cannot be separated from the vital role of ships as the most efficient mode of cargo transportation, where approximately $95 \%$ of the trade cargoes are transported by ship (RAEng, 2013).

The IMO noted that all maritime activities produced a total $\mathrm{CO} 2$ emissions as much as $2.2 \%$, in comparison to $\mathrm{CO} 2$ emissions due to all human activities (IMO, 2015). Furthermore, it was predicted to increase by $50 \%$ every year until it hit $250 \%$ in 2050 if not handled immediately (IMO, 2009).
In order to mitigate the risks and damage to the environment, the IMO had issued an index regulation as a comparison between the ship emissions levels and the capacity or performance through the Energy Efficiency Design Index (EEDI) (IMO, 2014) and Ship Energy Efficiency Management Plan (SEEMP) programme (IMO, 2012).

Therefore, the ship designer and the ship-owner must concern themselves with this regulation by paying attention to any design factors and what can be saved in consuming fossil energy.

Several methods that can be applied to conserve energy use in ships were described by Wang and Lutsey (2013) and Molland et al. (2014), where one of them is to maintain hull cleanliness from biofouling (roughness). 
Biofouling is a marine species that attach to submerged surfaces, including the ship hull. Biofouling makes the hull rough (not hydraulically smooth). The roughness causes the ship to experience additional friction resistance, with the result that the power requirements and fuel consumption increased (Schultz, 2007; Schultz et al., 2011; Molland et al., 2011; Monty et al., 2016, Demirel et al., 2017, Utama et al., 2017, Hakim et al., 2018; Hakim et al., 2019, Hakim et al., 2020).

Demirel et al. (2017) predicted the increase of resistance for the KRISO Container Ship (KCS) hull model using CFD, where the study results showed that the increase in friction resistance $\left(\triangle C_{F}\right)$ was up to $163.2 \%$ at 24 knots, where the surface hull condition was heavy calcareous fouling.

Monty et al. (2016) conducted an experiment on tubeworm roughness, then increasing the ship resistance of the FFG-7 Oliver Perry frigate was $23 \%$, and that of the very large crude carrier (VLCC) was $34 \%$. According to Kodama et al. (2000), a large bulk carrier had a composition of friction resistance around 80 and $90 \%$.

Data on the increase in fuel consumption recorded by Hakim et al. (2019) showed an increase in fuel consumption that was allegedly due to biofouling growth. Schultz et al. (2011) estimated the overall cost of ship maintenance, where it was a problem because biofouling reached US \$56 million per year for the entire DDG-51 class or U S \$1 billion over 15 years.

Biofouling can be overcome with antifouling paint, but the excellent quality of anti-fouling paint has a high price (Utama \& Nugroho, 2018). Moreover, the biocides used in antifouling paint, according to Rompay (2012), will have a harmful impact gradually in an aquatic environment, even though the chemical composition has been regulated by IMO (IMO, 2001).

International Towing Tank Conference (ITTC) recommended to finding and developing an accurate method to predict the increase in ship resistance due to biofouling, besides researching to improve the efficiency of energy use (ITTC, 2011). The studies on friction drag on rough surfaces were initiated by Nikuradse (1933) who popularized the sandgrain equivalent height roughness $\left(k_{s}\right)$. Granville $(1958 ; 1978)$ proposed a similarity law scaling procedure to predict friction drag on all objects covered in roughness. Practically, the empirical formula from Townsin (2003) has been recommended by ITTC (2008) to predict an increase in friction drag $(\triangle C F)$ due to roughness in the ship hull. In the recommendation, there is only $\Delta C F$ formula, and it does not mention an increase in other resistance components such as $\triangle C F$ and $\triangle C W$. However, CFD simulations conducted by Demirel et al. (2017) and Song et al. (2019) recently showed that roughness did not only affect the friction resistance, but the roughness also affected the pressure and wave resistance components.

In this paper, the study of the increase in ship resistances components due to roughness using wind-tunnel experiments and CFD simulations are explained. With the windtunnel experiment, the full viscous analysis could be carried out to further explore changes in the friction and pressure resistance only without the wave resistance. This series of analyzes wants to show that, the roughness not only affects the increase in friction resistance $(\Delta C F)$, but also it affects the increase in pressure resistance $(\Delta C P)$ on a ship hull.

For this experiment, two scaled-down ship hull models were tested, where one was smooth-walled, and another was rough-walled. The rough-walled model, the roughness was made from sandpaper with grit 100 or $k_{a}=162$ $\mu \mathrm{m}$ (ISO, 1998). With the same hull model, the CFD simulations with steady ReynoldsAveraged Navier-Stokes (RANS) were also carried out. The steady flow was chosen to reduce the computational load and was deemed sufficient to obtain the resistance value in the form of a single final value, not a value that changes with time (transient). In the simulations, the roughness function $\left(\Delta U^{+}\right)$used near-wall functions developed by Cebeci and Bradshaw 
(1977) based on Nikuradse's data, and this had been tried by Demirel et al. $(2014 ; 2017)$ also.

Finally, the experimental and numerical results were compared and analyzed about the increase in each component of the resistances due to roughness.

\section{Materials and Methods}

\section{Ship Resistance Components}

The total ship resistance, $R T$, can be divided into several resistance components, namely, the frictional resistance, $R_{F}$, and the residuary resistance, $R W$, as given by Equation 1 (Molland et al., 2011).

$$
R_{T}=R_{F}+R_{R}
$$

Friction resistance occurs because the fluid layer that attaches to the hull wall, which has the same velocity as the ship, rubs against the fluid layer that is stationary and located away from the wall. Residual resistance is a phenomenon of pressure which consists of wave resistance $R_{W}$ and viscous pressure $R P$. Hence residuary resistance $(R R)$ can be expanded into Equation 7.

$$
R_{T}=R_{F}+R_{W}
$$

$R P$ can be expanded further into $k R F$ as shown in Equation 3.

$R_{T}=R_{F}+k R_{F}+R_{W}=(1+k) R_{F}+R_{W}$

These resistance components are usually transformed in a non-dimensional form by dividing with dynamic pressure and wetted surface area (WSA), as shown in Equation 4. They would lead to Equation 5, where $C_{T}$ is the total friction coefficient, $C_{F}$ is the friction resistance coefficient, $C_{R}$ is the residual resistance coefficient, $C P$ is the viscous pressure coefficient, and $C W$ is the wave resistance coefficient, $\rho$ is the density of the used fluid, $S$ is WSA, and $U$ is the velocity. Note that $C_{W}$ is 0 due to the absence of waves for this case because the experiments use a wind-tunnel (a single phase of fluid).

$$
\begin{aligned}
& C_{T}=\frac{R_{T}}{\frac{1}{2} \rho S U^{2}} ; \quad C_{F}=\frac{R_{F}}{\frac{1}{2} \rho S U^{2}} ; \quad C_{P}=\frac{R_{P}}{\frac{1}{2} \rho S U^{2}} ; \quad C_{W}=\frac{R_{W}}{\frac{1}{2} \rho S U^{2}} \text { (4) } \\
& C_{T}=C_{F}+C P+C W=(1+k) C_{F}+C_{W}
\end{aligned}
$$

The difference in friction and pressure can be illustrated in Figure 1. The friction is a force arising from the presence of a contacting surface and moving on fluid. The force can occur because the fluid which contacts with the surface is held up then the fluid's velocity equal to zero.

As a result of fluid retention on the surface, the velocity profile has a gradation from zero to equal the freestream speed on far of surface, which is called the boundary layer. Then, pressure is a force generated due to the presence of fluid, which is blocked by the wall of object in normal direction of the area. Then, friction is the force that is parallel to the surface of the object, while the pressure is the force that is perpendicular to the surface of the object.

In a recommendation from ITTC (2008) for the total ship resistance formula (see Equation 6), there is a $\Delta C F$ variable as an additional resistance due to roughness. Here, $\Delta C_{F}$ is the increase in friction resistance, which was adopted from Townsin (2003). Then, $C_{A A}$ is the air resistance coefficient. In Equation 6, the roughness only affects to $\Delta C F$, and it does not mention the prediction for the changes in pressure or wave resistance $(\triangle C P$ and $\Delta C W)$.

$$
C_{T}=(1+k) C_{F}+C_{F}+C_{R}+\Delta C_{F}+C_{A A}
$$

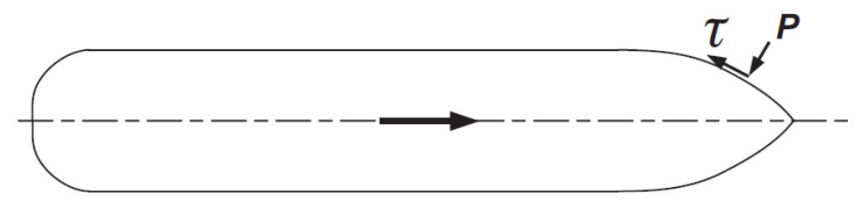

Figure 1: Friction and pressure acting on a ship hull (Molland et al., 2017) 


\section{Wind-tunnel Experiments}

In this study, the model used for testing was the cargo ship hull model, which has the dimensions shown in Table 1. The model was scaled down (1:216) to size matching with the test section of the wind-tunnel.

The hull model was cut from the baseline to the line draught, hence only the WSA was used (see Figure 2), and then it was mirrored. The wind-tunnel is a facility of energy laboratory facility owned by Politeknik Elektronika Negeri Surabaya, where its cross-section size is length $=1 \mathrm{~m}$, breadth $=0.4 \mathrm{~m}$, and height $0.4 \mathrm{~m}$. Here the ship model was attached to a USCELL SP2-C3 load cell as the force gauge.

The load cell and the system had been calibrated and validated using a standard object (such as a sphere, cylinder, and aerofoil) by Habibi (2017) with an uncertainty of less than $\pm 10 \%$.

Then, the model was placed in the middle of the test section with a holder.

Previously, the drag of the holder was tested first, then the actual force values obtained from the model. In the test section, the measured turbulence intensity of the wind-tunnel was 0.49\% (Habibi, 2017).

The two models prepared one for the smooth-walled hull and another for the roughwalled hull. For the rough-walled hull model case, the roughness grains were obtained from sandpaper, which then attached to the hull model.

The sandpaper used in the experiment has a grit number of 100 , or it has an average roughness height of $k_{a}=162 \mu \mathrm{m}$ (ISO, 1998).
Both models had been carried out with four different free stream velocities, namely 6,10 , 15 , and $20 \mathrm{~m} / \mathrm{s}$, where these, in turn, lead to Reynolds number $1.98 \times 10^{5} ; 3.31 \times 10^{5} ; 4.96 x$ $10^{5}$; and $6.61 \times 10^{5}$ respectively using Equation 7.

Where $\rho$ is the density of the fluid, $U$ is freestream velocity, $L$ is the length of the model, and $\mu$ is dynamic viscosity. The four-speeds were chosen because they are based on the best capabilities of the wind tunnel facility, where the best operation is at $5-20 \mathrm{~m} / \mathrm{s}$.

$$
\begin{aligned}
& \rho U L \\
& \operatorname{Re}=\mu
\end{aligned}
$$

\section{CFD Simulations}

This sub-section explains a method for conducting CFD simulations to solve the cases in this study. It consists of choosing numerical formulations, choosing a wall-function approach for roughness, making geometry and boundary conditions, generating the mesh, and generating the near-wall mesh.

In this study, a steady Reynolds-Averaged Navier-Stokes (RANS) method was used to solve the governing equations. These mass and momentum conservation equations were solved by the commercial CFD software ANSYS FLUENT. For incompressible flows, the averaged continuity and the momentum equations are given in Equation 8 and 9.

Here: $\bar{U}_{i}$ is the averaged velocity component; $P$ is the mean pressure; $\rho$ is the fluid density; $\mu$ is the dynamic viscosity; $u^{\prime}$ is the fluctuation velocity component; $\rho \overrightarrow{U U}$ is the Reynolds stress, $\bar{\tau}$ are the mean viscous stress tensor components, as given in Equation 10 (Fergizer \& Peric,

Table 1: The particular dimentions of models

\begin{tabular}{lrclrc}
\hline \multicolumn{1}{c}{ Item } & Value & Unit & Item & \multicolumn{1}{c}{ Value } & Unit \\
\hline LOA & 0.50 & $\mathrm{~m}$ & $\mathrm{~T}$ & 0.033 & $\mathrm{~m}$ \\
LPP & 0.47 & $\mathrm{~m}$ & $\nabla$ & $1.028 \times 10^{-3}$ & $\mathrm{~m}^{-3}$ \\
LWL & 0.49 & $\mathrm{~m}$ & WSA & 0.0565 & $\mathrm{~m}^{2}$ \\
B & 0.084 & $\mathrm{~m}$ & Cв & 0.743 & $\mathrm{~m}$ \\
\hline
\end{tabular}




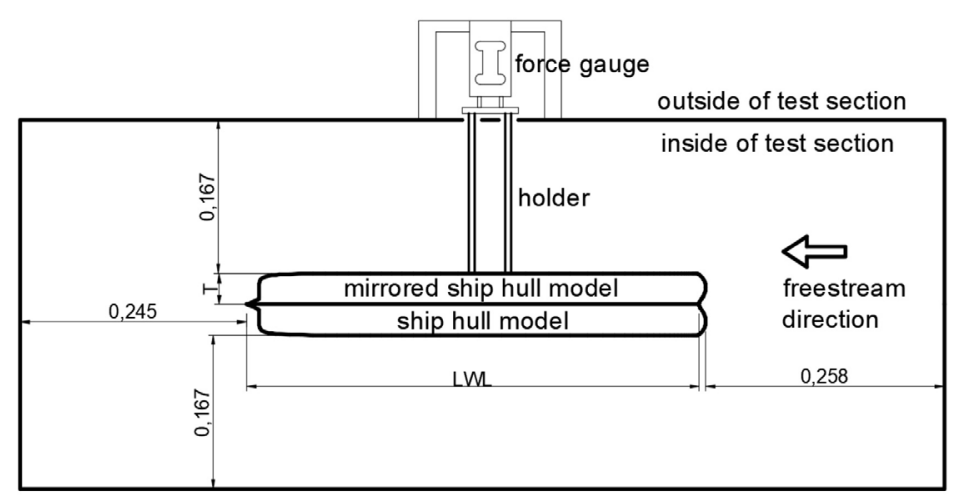

Figure 2: The ship model and its position in the test section

2010). The solver uses a finite volume method using a SIMPLE algorithm, which discretizes the governing equations where the gradient used least-squares cell-based.

The continuity and the momentumequations were discretized with a second-order equation, with the residual of numerical calculations were targeted less than $10^{-5}$.

$$
\begin{gathered}
\frac{\partial\left(\rho \bar{U}_{l}\right)}{\partial x_{i}}=0 \\
\frac{\partial\left(\rho \bar{U}_{l}\right)}{\partial t}+\frac{\partial}{\partial x_{i}}\left(\rho \bar{U}_{l} \bar{U}_{J}+\rho \overline{U_{l}^{\prime} U_{J}^{\prime}}\right)=-\frac{\partial \bar{P}}{\partial x_{i}}+\frac{\partial \overline{\tau_{l j}}}{\partial x_{j}} \\
\tau_{i j}=\mu\left(\frac{\partial \bar{U}_{l}}{\partial x_{j}}+\frac{\partial \bar{U}_{J}}{\partial x_{i}}\right)
\end{gathered}
$$

The Shear Stress Transport (SST) $k-\varepsilon$ turbulence model was used to complete the RANS equations. It blends the $k-\omega$ model near the wall and the $k-\varepsilon$ model in the far-field. The turbulence model consists of $k$ as turbulence kinetic energy and $\omega$ as a specific dissipation rate, where these were developed by Menter (1994). The kinetic energy equation is given in
Equation 11, and the dissipation rate equation is given in Equation 12. Detailed descriptions with these equations can be read on Menter (1994).

The kinetic energy and the momentum equations were discretized with second order upwind, and also with the residual of numerical calculations were less than $10^{-5}$.

The modeling of roughness here used the wall-function approach, which added roughness function. Wall-functions are mathematical expressions that can model the viscosity affected to the velocity profile of the boundary layer. It can be assumed that the near-wall cell lies within the logarithmic region. In this study, the standard wall function was used, which has discontinuities between the viscous sublayer and the log-law region, where the viscous sublayer is given in Equation 13 and the log-law region in Equation 14.

Furthermore, to represent of roughness effect, a roughness function $\left(\Delta U^{+}\right)$is added to Equation 14, becoming Equation 15, where it causes a downward shift in the velocity profile in the log-law region. Where, $U^{+}$is the nondimensional of mean velocity at each

$$
\begin{gathered}
\frac{D \rho k}{\mathrm{Dt}}=\tau_{i j} \frac{\partial U_{i}}{\partial \mathrm{x}_{i}}-\beta^{*} \rho \omega k+\frac{\partial}{\partial x_{i}}\left\lceil\left(\mu+\sigma_{k} \mu_{t}\right) \frac{\partial k}{\partial \mathrm{x}_{i}}\right\rceil \\
\frac{D \rho \omega}{\mathrm{Dt}}=\frac{\gamma}{v_{t}} \tau_{i j} \frac{\partial U_{i}}{\partial \mathrm{x}_{i}}-\beta \rho \omega^{2}+\frac{\partial}{\partial x_{i}}\left\lceil\left(\mu+\sigma_{\omega} \mu_{t}\right) \frac{\partial \omega}{\partial \mathrm{x}_{i}}\right\rceil+2 \rho\left(1-F_{1}\right) \sigma_{\omega 2} \frac{1}{\omega} \frac{\partial k}{\partial x_{i}} \frac{\partial \omega}{\partial x_{i}}
\end{gathered}
$$


height of normal distance from the wall (as nondimensional, $y^{+}$). Then $\kappa$ is the Von Karman constant, and $B$ is the intercept log-wall for smooth surfaces. 7

$$
\begin{gathered}
U^{+}=y^{+} \\
U^{+}=\frac{1}{\kappa} \ln \left(y^{+}\right)+B \\
U^{+}=\frac{1}{\kappa} \ln \left(y^{+}\right)+B-\Delta U^{+}
\end{gathered}
$$

The CFD software code has a default roughness function that adopted from Cebeci and Bradshaw (1977) based on Nikuradse's data (1933). The roughness function is given in Equation 16, where it is divided into three parts, namely hydraulically smooth, transition, fully rough regime. Here: $k^{+}$is roughness Reynolds number, in form $k U v^{-1} ; C$ is the roughness constant, taken 0.253 to follows the Nikuradse curve (Atencio \& Chemoray, 2019); $k_{s}$ is equivalent sand-grain roughness height.

In these simulations, $k_{s}$ was varied from: 0 , 30, 300, 1000, and $3000 \mu \mathrm{m}$. These variations were taken from Schultz and Flack (2007), where some roughness type of biofouling and coating had been determined to $k_{s}$ value. However, Schultz and Flack (2007) used the different roughness function with that used in this simulation. The differences in roughness function can be seen in Figure 3.

From Figure 3, there were differences in the roughness function used in this simulation from those proposed by Schultz and Flack (2007). The difference was in the transition region. Therefore, the results of this simulation must be verified where it was, whether it was in the transitional regime or in fully rough regime using $k^{+}$value. To calculate the value of $k^{+}$can use Equation 17. Where $U$ is the friction velocity that can be approximated by Equation 18. Then, $v$ is kinematic viscosity.

$$
k_{s}^{+}=\frac{k_{s} U_{\tau}}{n}
$$

$$
U_{\tau}=\sqrt{ } \frac{C_{F}}{2} U_{\infty}
$$

The size of the computational domain was adjusted to represent the test section size of the wind tunnel. Because the domain had two symmetry axes, namely centreline and load line, the domain could be modeled for only a quarter of the full size to reduce the computational load. This configuration was chosen based on the best engineering adjustment to simulate this case. The upstream distance was set to have length $1 \mathrm{~L}$, and the downstream was 3L. Figure 4 shows the details of the domain size and the boundary conditions, which set up as follows: A was velocity inlet; B was pressure outlet; C was vertical symmetry (free slip wall); D was horizontal symmetry (free slip wall); E and F (the test section wall) were no-slip walls, and $\mathrm{H}$ (the hull model) was no-slip wall.

The boundary conditions were set based on realistic flow conditions. The test section had a boundary surrounded by walls that the wall had a friction effect, then the no-slip condition had been applied. In the computational domain, the density of the air as input was $1.204 \mathrm{~kg} / \mathrm{m}^{3}$, and dynamic viscosity was $1.82 \times 10^{-5} \mathrm{~kg} / \mathrm{ms}$.

Figure 5 shows a mesh arrangement consisting of 4 (four) millions unstructured elements, which has a grid arrangement inflated

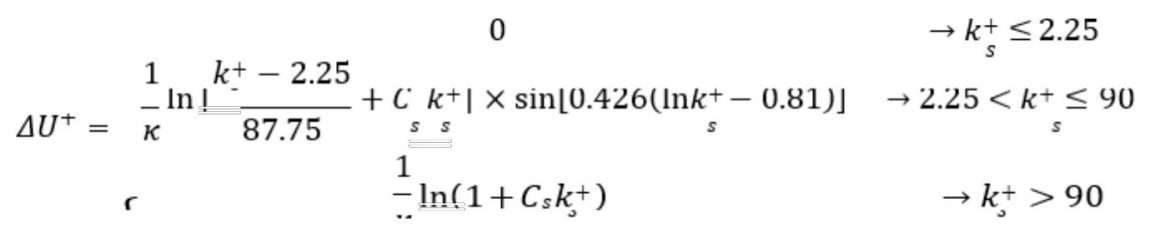




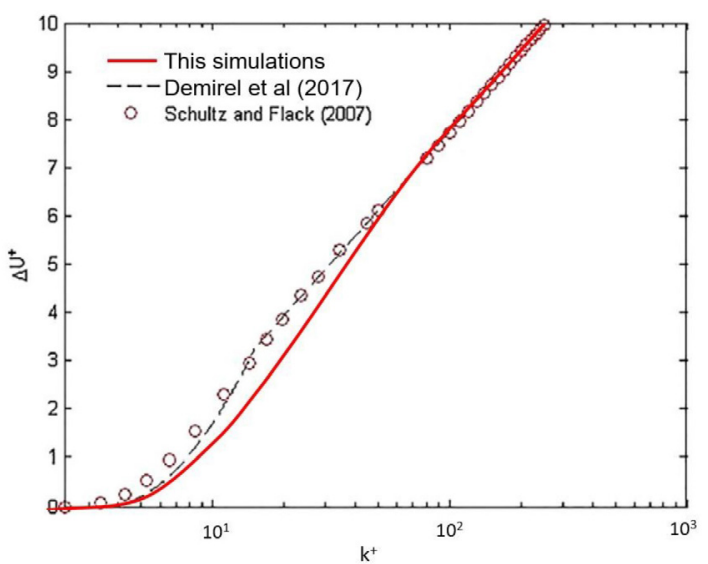

Figure 3: The roughness functions position on the ship hull model wall of the ship hull model with prism elements. The inflation is needed to get the best value of $y^{+}$, where it was set $y^{+} \sim 1$ or $30<y^{+} \leq 300$ to keep off the buffer zone. Then the number and arrangementof these grids must be tested with grid-sensitivity testing for accurate simulations.
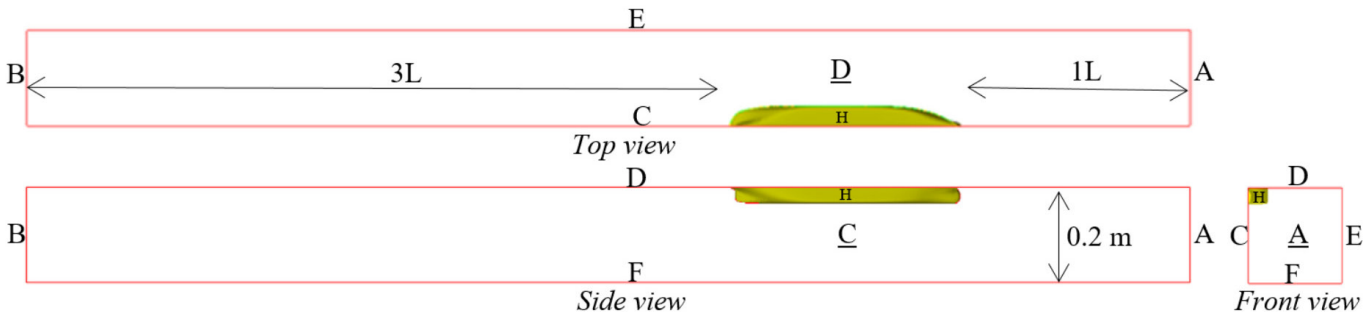

Figure 4: The domain size and boundary conditions
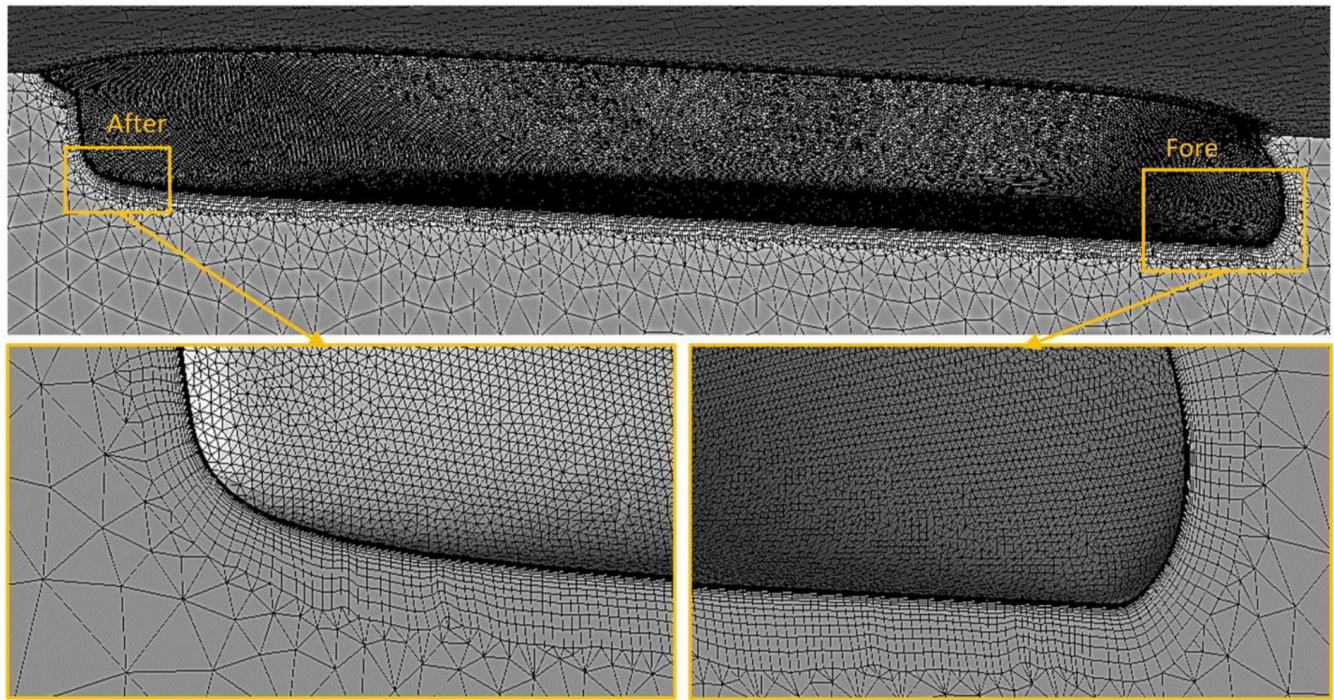

Figure 5: The appearance of mesh arrangement 


\section{Result and Discussion}

The results of the experiment and the CFD simulation will be described in this section. The explanation is as follows: 1. The experimental results were reviewed; 2 . The CFD simulation results were also reviewed; 3 . The $C_{T}$ results both from the experiment and the simulation were compared and analyzed to determine the $k_{s}$ value for the $k_{a}$ value; 4 . The $C_{F}$ results were compared and analyzed; 5. The $C P$ results were compared and analyzed; 6. The effect of roughness on the resistance components was also analyzed.

\section{Experimental Results}

The wind-tunnel experiments were carried out. The results were in the measured force data from the strain gauge as $R T$ which then converted to $C_{T}$ with Equation 4. Each variation was tested repeatedly five times in five different times (days). The first day, the first data was measured once for each speed variation.

The second day, the second data was measured once for each variation of speed and so on until the fifth day. The results were counted the mean and uncertainty. The uncertainty method used was uncertainty on repeated measurements (random uncertainty), that described in Equation 19 and 20. Where, $x_{0}$ is measurement results that are close to actual values, $\Delta x$ is measurement uncertainty, dan $N$ is the number of measurements made.

$$
\begin{gathered}
x_{0}=\frac{x_{1}+x_{2}+x_{3}+\cdots+x_{N}}{N}=\frac{\sum x_{i}}{N} \\
\Delta x=\frac{1}{N} v \frac{N \sum x_{i}^{2}-\left(\sum x_{i}\right)^{2}}{N-1}
\end{gathered}
$$

Based on the systematic uncertainty of the wind-tunnel measurements of $\pm 10 \%$ (Habibi, 2017), the total uncertainty is the result of random uncertainty plus the $\pm 10 \%$ systematic uncertainty. Therefore, the uncertainty was $\pm 11.17 \%$ for $\operatorname{Re}=1.94 \times 105, \pm 10.37 \%$ for $\operatorname{Re}$ $=3.24 \times 105, \pm 10.18 \%$ for $\mathrm{Re}=4.86 \times 105$, and $\pm 10.11 \%$ for $\operatorname{Re}=6.48 \times 105$.

\section{CFD Results}

The CFD simulations were carried out with the first step was grid-sensitivity analysis. A grid- sensitivity analysis was needed to get accurate results, where the sensitivity value was obtained from how much change of the result if the order and number of grids were changed. Anderson (1995) gave this sensitivity value must be below $2 \%$. For the sensitivity analysis, the grid arrangement was made into several arrangements.

First was coarse, wherein all outsideboundary conditions, the maximum size of the element was set around $\mathrm{L} / 100$, then for the hull, it was set L/1000 (created around 2 million elements).

The second was medium, where the boundary conditions were set $\mathrm{L} / 100$, then the hull was set L/2000 (created around 4 million elements). The third was fine, where the boundary conditions were set $\mathrm{L} / 100$, then the hull was set L/4000 (created around 8 million elements). In Table 2, the result of the grid-sensitivity analysis is shown, where the results showed that with around four million elements, the simulation could be accurate and could be used for the other variations because the sensitivity value with more elements arranged was $0.16 \%$ (below $2 \%$ ).

A verification study was carried out to show the capability of the proposed model and

Table 2: The grid-sensitivity analysis result

\begin{tabular}{lrcc}
\hline Mesh configuration & Number of elements & $\boldsymbol{R} \boldsymbol{T} \mathbf{x} \mathbf{1 0}^{\mathbf{3}}(\mathbf{N})$ & $\Delta \boldsymbol{R} \boldsymbol{T}$ \\
\hline Coarse & $2,229,871$ & 6.999 & - \\
Medium & $4,454,101$ & 6.699 & $4.49 \%$ \\
Fine & $8,184,959$ & 6.688 & $0.16 \%$ \\
\hline
\end{tabular}


the software for particular calculations. The discretization error estimation method used the Gris Convergence Index (GCI) (Celik et al., 2008), with the result: $r 21, r 32=\sqrt{ } 2 ; \varnothing 1=6.688$; $\varnothing 2=6.699 ; \varnothing 3=6.999 ; p a=9.539 ; \varnothing \operatorname{ext} 21$ $=6.748$; ea $21=0.164 \%$; eext $21=0.399 \%$; GCIfine $21=0.16 \%$. Therefore, the numerical uncertainty of these simulations was $\pm 0.16 \%$.

The next verification study, which aims to see where the position of the simulation results placed on the roughness function. To calculate the study, it used Equation 17 to find the $k+$ value. The calculation results can be seen in Table 3. From these results, not all variations of the simulations occurred in the fully rough regime, but some also occur in transition regimes.

Fully rough regimens only occurred for variations in $k s 1000$ and $3000 \mu \mathrm{m}$, as well as $k s$ $300 \mu \mathrm{m}$ for the velocity of $20 \mathrm{~m} / \mathrm{s}$ only.

A validation study was also carried out for these simulations. The validation study was by comparing the numerical result of the smooth- walled model with the empirical formula of friction coefficient $\left(C F_{R}\right)$ from ITTC 1957 (2002) as reference (see Equation 21). The results showed that there were less than $1 \%$ differences between the numerical and the ITTC 1957, see Table 5 and Figure 9. With the differences was less than $1 \%$ from these correlation studies, then it could be used as a benchmark for the roughwalled model simulations.

$$
C_{F_{S}}-\frac{0.075}{\left(\log _{1 \cup} R e-2\right)^{2}}
$$

In the numerical simulation, the resistance components could be separated automatically with the CFD software. Then, the simulation results $\left(C T, C_{F}\right.$, and $\left.C_{P}\right)$ were compared and analyzed in the next subsection.

\section{Total Resistance Results}

In this subsection, the total resistance results $(C F)$ from the experiments and the CFD, both the smooth-walled model and rough-walled

Table 3: The $k_{s}^{+}$calculation results, the italic numbers are the transition regimen and the bold numbers are the fully rough regime

\begin{tabular}{ccccc}
\hline \multirow{2}{*}{$\infty(\mathbf{m} / \mathbf{s})$} & \multicolumn{3}{c}{$\boldsymbol{k}_{s}^{+}$} \\
\cline { 2 - 5 } & $\boldsymbol{k}_{\boldsymbol{s}} \mathbf{3 0} \boldsymbol{\mu \mathbf { m }}$ & $\boldsymbol{k}_{\boldsymbol{s}} \mathbf{3 0 0} \boldsymbol{\mu m}$ & $\boldsymbol{k}_{s} \mathbf{1 0 0 0} \boldsymbol{\mu m}$ & $\boldsymbol{k}_{s} \mathbf{3 0 0 0} \boldsymbol{\mu m}$ \\
\hline 6 & 2.82 & 29.87 & $\mathbf{1 0 8 . 3 0}$ & $\mathbf{3 6 4 . 5 4}$ \\
10 & 4.42 & 47.35 & $\mathbf{1 7 7 . 0 3}$ & $\mathbf{5 9 6 . 3 6}$ \\
15 & 6.33 & 69.14 & $\mathbf{2 6 1 . 9 5}$ & $\mathbf{8 7 5 . 2 0}$ \\
20 & 8.20 & $\mathbf{9 1 . 0 3}$ & $\mathbf{3 4 8 . 3 2}$ & $\mathbf{1 1 4 6 . 3 5}$ \\
\hline
\end{tabular}

Table 4: Comparison of the $\mathrm{Cr}$ result,was based on $\Delta \mathrm{Cr}_{s}$ from the experiment

\begin{tabular}{|c|c|c|c|c|c|c|c|}
\hline \multirow{4}{*}{$\operatorname{Re} \times 10^{-}$} & \multicolumn{2}{|c|}{ Smooth-walled } & \multirow{2}{*}{\multicolumn{5}{|c|}{$\begin{array}{c}\text { Rough-walled } \\
C_{T_{R}}(\%)\end{array}$}} \\
\hline & \multirow{3}{*}{$\begin{array}{c}C T_{S} \times 10^{3} \\
\text { Exp. }\end{array}$} & \multirow{3}{*}{$\frac{\Delta C T_{S}(\%)}{C F D}$} & & & & & \\
\hline & & & & $\left(k_{s}\right.$ in & & Exp. & $n \mu \mathrm{m})$ \\
\hline & & & 30 & 300 & 1000 & 3000 & 162 \\
\hline 1.94 & 10.263 & -0.76 & 1.81 & 11.06 & 25.61 & 49.85 & 31.85 \\
\hline 3.24 & 9.087 & -1.05 & 2.36 & 13.73 & 34.69 & 61.18 & 41.57 \\
\hline 4.86 & 8.247 & -1.04 & 3.09 & 17.92 & 43.20 & 69.33 & 52.95 \\
\hline 6.48 & 7.745 & -1.42 & 3.38 & 21.61 & 50.22 & 73.70 & 60.60 \\
\hline
\end{tabular}


model, are discussed. The comparison of the differences in values for $C_{S}$, and $C T_{R}$ is shown in Table 4 and plotted in Figure 6.

In Table 4, it can be seen for the smoothwalled case $\left(C_{T}\right)$, that the differences of the CFD simulation results against the experimental results were from $-0.76 \%$ (for $\mathrm{Re}=19.4 \times 10^{5}$ ), $20-1.05 \%$ (for $\operatorname{Re}=3.24 \times 10^{5}$ ), $-1.04 \%$ (for $\mathrm{Re}$ $=4.86 \times 10^{5}$ ), and $-1.42 \%$ (for $\operatorname{Re}=6.48 \times 10^{5}$ ). The difference value was very small enough, with the mean value $1.07 \%$. Also it can be seen in Figure 6, that the $C_{T_{S}}$ curves, between the experiments and the CFD, were mostly matched each other. Thus, this can be used as confidence reference results for other variations (the roughwalled models).

For the rough-walled model results $\left(C_{R}\right)$, they were arranged in the form of $\Delta C T_{R}$, where $C_{T_{S}}$ from the experimental results were used as a reference comparison. Then, $\Delta C T_{R}$ were tabulated in Table 3 and plotted in Figure 6. Both in the simulation and experimental results, roughness caused an increase in the total resistance, $\Delta C T_{R}$. The total resistance increased along in the increase in $k_{s}$. Since Reynolds number increased, then $\Delta C T_{S}$ also increased. For example in the model with the roughness of $k$ s $=30 \mu \mathrm{m}, \Delta C T_{R}$ was $1.81 \%$ for $\mathrm{Re}=1.94 \times 10^{5^{s}}$, $\Delta C T_{R}$. The total resistance increased along in the increase in $k_{s}$. Since Reynolds number increased, then $\Delta C T_{R}$ also increased.

For example, in the model with the roughness of $k_{\mathrm{s}}=30 \mu \mathrm{m}, \Delta C T_{R}$ was $1.81 \%$ for $\operatorname{Re}=1.94 \times 10^{5}, \Delta C T_{R}$ was $2.36 \%$ for $\mathrm{Re}=$ $3.24 \times 10^{5}, \Delta C T_{R}$ was $3.09 \%$ for $\mathrm{Re}=4.86 \times 10^{5}$, and $\Delta C T_{R}$ was $3.38 \%$ for $\operatorname{Re}=6.48 \times 10^{5}$. Likewise with the experimental results, where it used $k_{a}=162 \mu \mathrm{m}$, then $\Delta C T_{R}$ was $31.85 \%$ for $\mathrm{Re}=1.94 \times 10^{5}, \Delta C_{T_{R}}$ was $41.57 \%$ for $\mathrm{Re}=$ $3.24 \times 10^{5}, \Delta C T_{R}$ was $52.95 \%$ for $\mathrm{Re}=4.86 \times 10^{5}$, and $\Delta C T_{R}$ was $60.60 \%$ for $\mathrm{Re}=6.48 \times 10^{5}$. Of course, the roughness rate could increase the total resistance, for example in the case $\mathrm{Re}$ $=1.94 \times 105$, then $\Delta C T_{R}$ was $1.81 \%$ for $k_{s}=30$ $\mu \mathrm{m}, \Delta C T_{R}$ was $11.06 \%$ for $k_{s}=300 \mu \mathrm{m}, \Delta C T_{R}$ was $25.61 \%$ for $k s=1000 \mu \mathrm{m}$, and $\Delta C T_{R}$ was $49.85 \%$ for $k s=3000 \mu \mathrm{m}$. The highest $\Delta C T_{R}$ was $73.70 \%$, which was the highest $\operatorname{Re} 12$ and $k_{s}$.

Based on the results, it is a big problem because the roughness will increase fuel consumption or reduce the ship's speed, which results in longer travel time so that it will increase fuel consumption too. When the fuel consumption increase, then the level of carbon emissions in the air will also increase.

$k_{s}=30 \mu \mathrm{m}, \Delta C T_{R}$ was $11.06 \%$ for $k_{s}=300$ $\mu \mathrm{m}, \Delta C T_{R}$ was $25.61 \%$ for $k_{s}=1000 \mu \mathrm{m}$, and $\Delta C T_{R}$ was $49.85 \%$ for $k_{s}=3000 \mu \mathrm{m}$. The highest

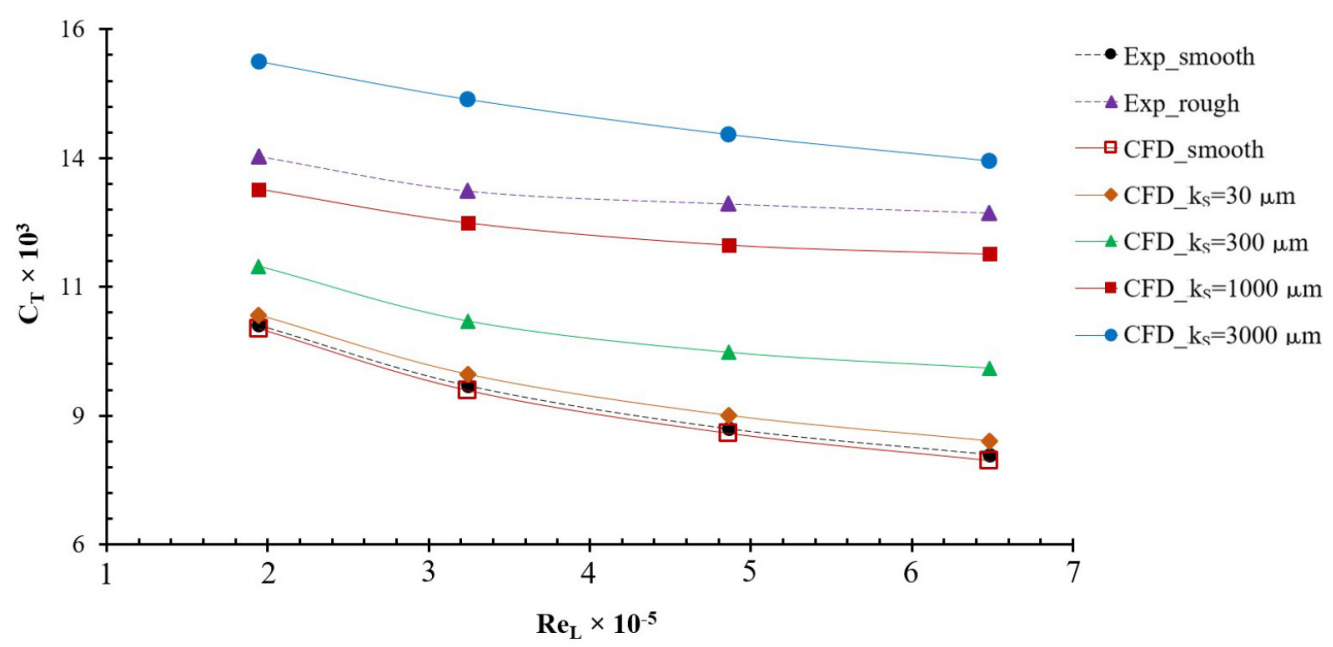

Figure 6: Comparison of the $\mathrm{Cr}$ results against Reynolds number 
$\Delta C T_{R}$ a was $73.70 \%$, which was the highest Re 12 and $k_{s}$.

Based on the results, it is a big problem because the roughness will increase fuel consumption or reduce the ship's speed, which results in longer travel time so that it will increase fuel consumption too. When the fuel consumption increase, then the level of carbon emissions in the air will also increase.

Based on the plot in Figure 6, the result of the experimental rough-walled model was located between the results of $k_{s}=1000 \mu \mathrm{m}$ and $k_{s}=3000 \mu \mathrm{m}$.

Though the rough model has an average roughness height $\left(k_{a}\right)$ of $162 \mu \mathrm{m}$, this showed that the value of $k_{s}$ could not be equated or determined just from the average height of a roughness $\left(k_{a}\right)$.

In accordance with what was stated by Utama et al. (2018), the $k_{a}$ parameter, was less accurate to determine the completion of an increase in drag due to roughness. Thus, it will be a problem to do an analysis or simulation for industrial purposes, where to get the appropriate $k_{s}$ value is not simple.
The $k_{s}$ value of the experimental model (the sandpaper roughness of $k_{a}=162 \mu \mathrm{m}$ ) was tried to be predicted using non-linear regression according to the numerical results data.

The non-linear regression process is shown in Figure 7, then the $k_{s}$ value for each Reynolds number could be obtained. They were $1400 \mu \mathrm{m}$ for $\operatorname{Re}=1.94 \times 10^{5}, 1375 \mu \mathrm{m}$ for $\mathrm{Re}=3.24 \times 10^{5}$, $1525 \mu \mathrm{m}$ for $\mathrm{Re}=4.86 \times 10^{5}$, and $1600 \mu \mathrm{m}$ for $6.48 \times 10^{5}$. All the $k_{s}$ values were averaged. Therefore, the $k_{a}=162 \mu \mathrm{m}$ was correlated with the $k_{s}=1475 \mu \mathrm{m}$.

The predicted $k_{s}$ value $(1475 \mu \mathrm{m})$ was inputted to the numerical model and recomputed as same as the numerical calculation before. Then, the new numerical results were compared with the experimental results and plotted in Figure 8. It can be seen from Figure 8, that the $C T_{R}$ results from predicted $k_{s}$ were very close to that of the $k_{a}$ from the experiment, with the difference below than $\pm 0.97 \%$. Therefore, it could be concluded that in this case the experimental model with sandpaper roughness $k_{a}=162 \mu \mathrm{m}$ was equal to the numerical model with the $k_{s}=1475 \mu \mathrm{m}$.

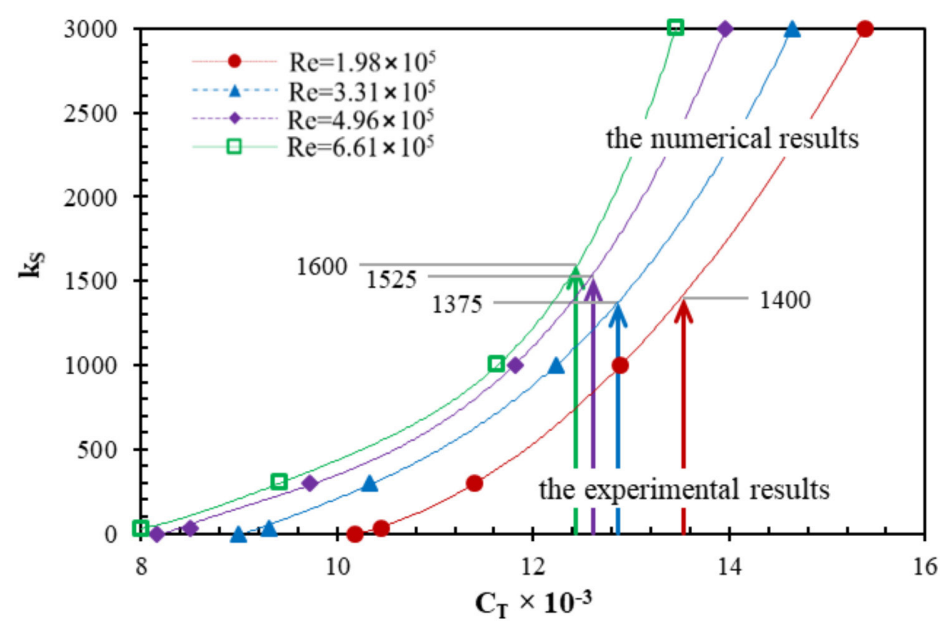

Figure 7: Non-linear regression to predict the $k_{s}$ value from the $k_{a}$ value 


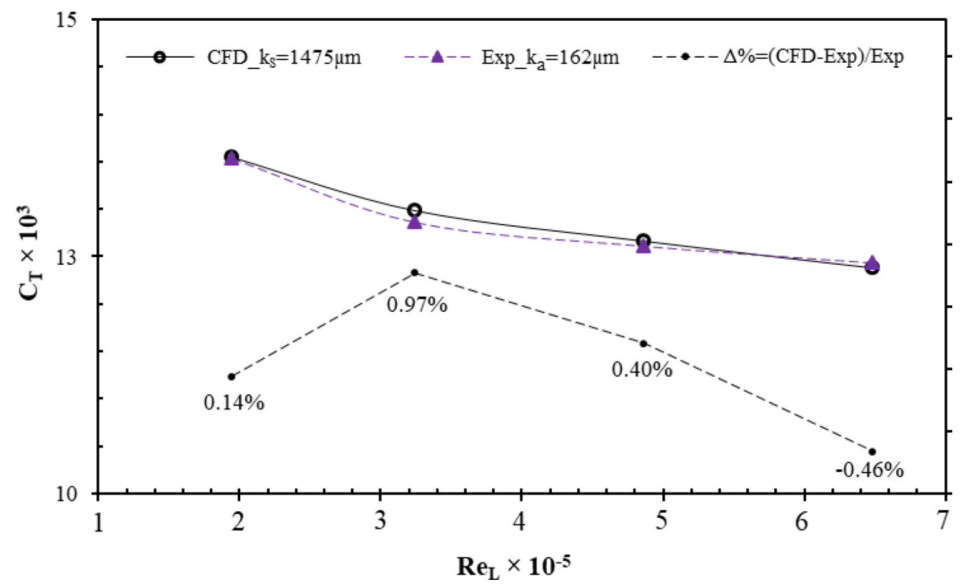

Figure 8: Comparison of the $\mathrm{Cr}$ results against Reynolds number

\section{Friction Resistance Results}

The increase in friction resistance due to roughness from the CFD only is discussed in this subsection, because just the CFD that can separate the total resistance into the friction and pressure resistance. All the CFD results for the friction resistance $(\Delta C F)$ were arranged in Table 5 and plotted in Figure 9.

In Table 5, it can be seen for the smoothwalled case $\left(C_{F}\right.$, that the differences of the CFD simulation results against ITTC 1957 were not more than $0.62 \%$ (on $\operatorname{Re}=6.48 \times 105$ ), where the CFD results had a lower value than that of ITTC 1957. Then the differences of the experimental results against ITTC were less than $1.54 \%$ (on $\operatorname{Re}=3.24 \times 105)$. These results showed that the experiments and the CFD were very close to ITTC formula, with a difference of less than $2 \%$.
Moreover, this could be a good foundation for other simulation results using the rough-walled surfaces.

For the rough-walled model results $\left(C_{F_{R}}\right)$, they were arranged in the form of $\Delta C_{F_{R}}$, where $C_{F_{S}}$ from the ITTC 1957 was used as a referred comparison. Then, $\Delta C F_{R}$ were tabulated in Table 5, and plotted in Figure 9. In the simulation results, roughness caused an increase in the friction resistance, $\Delta C_{F_{R}}$. The friction resistance increased along in the increase in $k_{s}$. Since Reynolds number increased, then $\Delta C_{F_{R}}$ also increased. For example in the model with the roughness of $k_{s}=30 \mu \mathrm{m}, \Delta C_{F_{R}}$ was $3.32 \%$ for $\mathrm{Re}=1.94 \times 10^{5}, \Delta C_{F_{R}}$ was $4.38 \%$ for $\mathrm{Re}=$ $3.24 \times 10^{5}, \Delta C_{F_{R}}$ was $5.09 \%$ for $\mathrm{Re}=4.86 \times 10^{5}$, and $\Delta C_{F_{R}}$ was $5.98 \%$ for $\mathrm{Re}=6.48 \times 10^{5}$. The roughness rate could increase the friction

Table 5: Comparison of the $\mathrm{Cr}$ result,was based on $\Delta \mathrm{Cr}_{s}$ from the experiment

\begin{tabular}{|c|c|c|c|c|c|c|c|}
\hline \multirow{4}{*}{$\operatorname{Re} \times 10^{-5}$} & \multicolumn{3}{|c|}{ Smooth-walled } & \multicolumn{3}{|c|}{ Rough-walled } & \\
\hline & $C_{F_{S}} \mathbf{x 1 0 ^ { 3 }}$ & $\Delta C_{F_{S}}(\%)$ & \multicolumn{5}{|c|}{$C_{F_{R}}(\%)$} \\
\hline & \multirow[t]{2}{*}{ ITTC } & \multirow{2}{*}{$k_{s} \mathbf{0} \mu \mathrm{m}$} & \multicolumn{5}{|c|}{$k_{s}$ in $\mu \mathrm{m}$} \\
\hline & & & 30 & 300 & 1000 & 1475 & 3000 \\
\hline 1.94 & 6.934 & -0.18 & 3.32 & 16.20 & 37.52 & 46.72 & 73.12 \\
\hline 3.24 & 6.085 & -0.02 & 4.38 & 19.83 & 50.73 & 62.79 & 90.06 \\
\hline 4.86 & 5.518 & -0.49 & 5.09 & 25.20 & 61.77 & 77.25 & 100.64 \\
\hline 6.48 & 5.162 & -0.62 & 5.98 & 30.52 & 71.97 & 86.32 & 106.96 \\
\hline
\end{tabular}


resistance drastically also, for example in the case $\operatorname{Re}=1.94 \times 10^{5}$, then $\Delta C F$ was $3.32 \%$ for $k_{s}=30 \mu \mathrm{m}, \Delta C_{F}$ was $16.20 \%$ for $k_{s}=300 \mu \mathrm{m}$, $\Delta C_{F_{R}}$ was $37.52 \%$ for $k_{s}=1000 \mu \mathrm{m}, \Delta C_{F_{R}}$ was $46.72 \%$ for $k_{s}=1475 \mu \mathrm{m}$, and $\Delta C F_{R}$ was $73.12 \%$ for $k_{s}=3000 \mu \mathrm{m}$. The highest $\Delta C_{F_{R}}$ was $106.96 \%$, which was the highest Re and $k_{s} .27$.

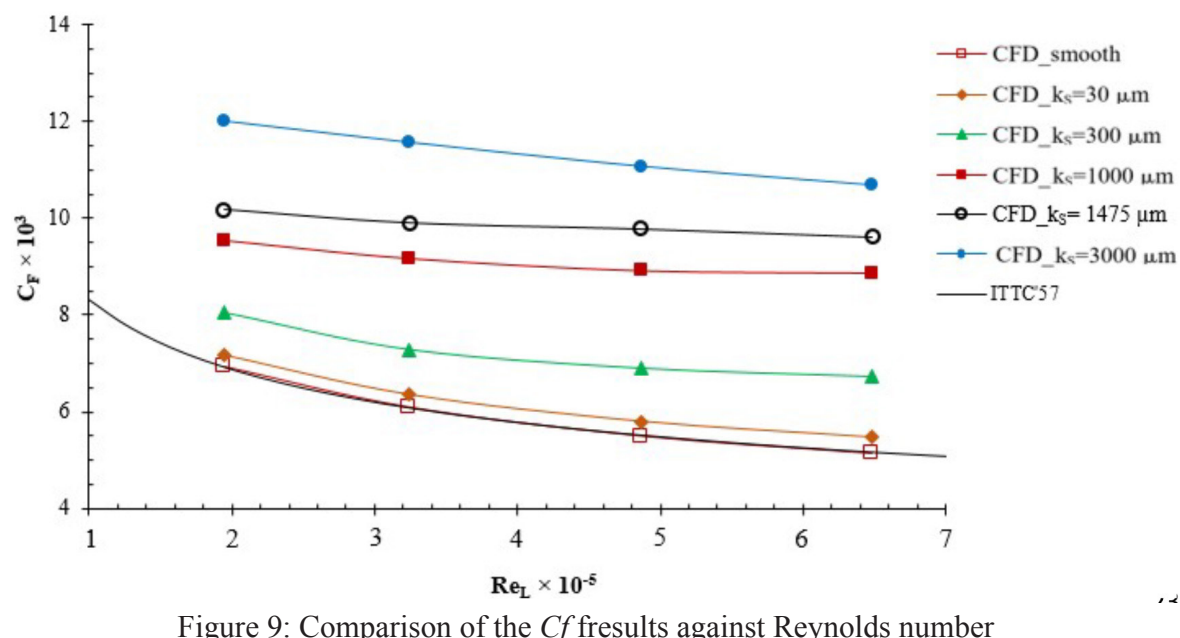

There were differences in the distribution of local friction $(C f)$ for each roughness condition, as shown in Figure 10. It can be seen that between the smooth model $\left(k_{s}=0 \mathrm{~mm}\right)$ and the $k_{s}=30 \mu \mathrm{m}$, there was no significant difference. Only at the $k_{s}=300 \mu \mathrm{m}$ and the $k_{s}=3000 \mu \mathrm{m}$, the difference in $C f$ distribution was noticeable. The tendency of the difference distribution in the stern part of the ship hull models was not significant, where it can be seen to the blue color distribution in the stern part. However, in the bow part to the amidships, the difference was very noticeable, where it can be seen to the model with $k_{s}=$ $3000 \mu \mathrm{m}$ that the color distribution was greener than that of the smooth model. This happening shows that the shape of the hull is also believed to have a role in changing the friction resistance due to roughness. The effect of the hull shape on the increase in ship resistance due to roughness needs to be explored for further research, for example, suppose the effect of roughness on a catamaran.

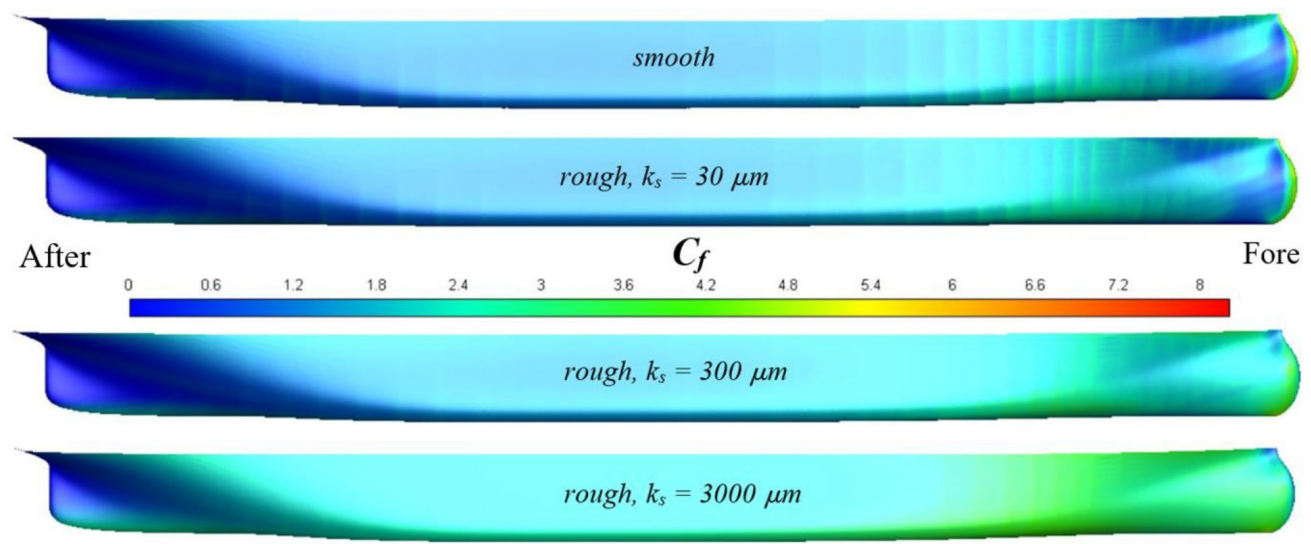

Figure 10: The local $C f$ distribution for differences roughness condition 


\section{Pressure Resistance Results}

In this subsection, the effect of roughness on $C P_{R}$ will be discussed. In the numerical simulations, the actual $C_{P_{R}}$ could be calculated and presented, even though in the case with roughness condition. However, in the CFD simulations, the results could be separated between $C_{F_{R}}$ (friction) and $C_{P_{R}}$ (pressure), even for rough surface conditions, therefore the actual $C_{P_{R}}$ could be counted. The results of the comparison of $C P_{R}$ values were tabulated in Table 6 and plotted in Figure 11.

It can be seen in Table 6 that the roughness could increase the pressure resistance. The increase in pressure resistance $\left(\Delta C P_{R}\right)$ was greatly influenced by the roughness conditions (represented as $k_{s}$ ), and also Reynolds number. When the $k_{s}$ increased, then the $\Delta C P_{R}$ also increased. The $\Delta C P_{R}$ increased also along Reynolds number increased. For example in models with the roughness of $k_{s}=300 \mu \mathrm{m}, \Delta C P_{R}$ was $1.91 \%$ for $\mathrm{Re}=1.94 \times 10^{5}, \Delta C P_{R}$ was $4.63 \%$ for $2 \mathrm{Re}=3.24 \times 10^{5}, \Delta C P_{R}$ was $5.47 \%$ for Re $=4.86 \times 10^{5}$, and $\Delta C P_{R}$ was $7.03 \%$ for $\mathrm{Re}=$ $6.48 \times 10^{5}$.

The roughness rate could increase the friction resistance also, for example in the case $\mathrm{Re}=4 \quad 1.94 \times 10^{5}$, then $\Delta C P_{R}$ was $0.62 \%$ for $k$ $=30 \mu \mathrm{m}, \Delta C_{P_{R}}$ was $1.91 \%$ for $k_{\mathrm{s}}=300 \mu \mathrm{m}, \Delta C_{P}$ was $52.83 \%$ for $k_{s}=1000 \mu \mathrm{m}, \Delta C P_{R}$ Was $3.39 \%$ for $k_{s}=1475 \mu \mathrm{m}$, and $\Delta C P_{R}$ was $3.40 \%$ for $k_{s}=$
$3000 \mu \mathrm{m}$. The highest $\Delta C P_{R}$ was $10.57 \%$, which was the highest $\operatorname{Re}$ and $k_{s}$.

If this is noted that the increase in pressure resistance, which is due to roughness, is not as drastic as the friction resistance. Although not drastic, the increase in pressure resistance is quite a contribution, so it also needs attention. This pressure resistance is closely related to the shape of the ship hull, so with different ship hulls, the increase in pressure resistance, which caused roughness, will be different also.

A visualization of the difference in the velocity contour between the smooth model and the rough model is shown in Figure 12. It can be seen that there was a difference in velocity contour (thickness of the boundary layer) in the middle towards the stern part of the ship hull models. The smooth-walled model upper part had the thinner velocity contour than that of the rough-walled model (bottom part). Following the law of conservation of momentum, if there was a difference in the velocity, then there will be a difference in the pressure. This phenomenon was also explained in a study by Demirel et al. (2017a) and Song et al. (2019), where the roughness could change the pressure distribution on the ship hull, especially at the stern. The pressure contour was not shown because the difference was minor that it was challenging to discover, therefore only this velocity contour could be seen as the differences.

Table 6: Comparison of the $C P$ result, $\triangle C P$ is based on $C_{P}$ from the CFD

\begin{tabular}{|c|c|c|c|c|c|c|}
\hline \multirow{4}{*}{$\operatorname{Re} \times 10^{-5}$} & \multirow{2}{*}{$\begin{array}{c}\text { Smooth-walled } \\
C P_{S} \times 10^{3} \\
\end{array}$} & \multicolumn{5}{|c|}{ Rough-walled } \\
\hline & & \multicolumn{5}{|c|}{$C_{F_{R}}(\%)$} \\
\hline & \multirow{2}{*}{$k_{s} 0 \mu \mathrm{m}$} & \multicolumn{5}{|c|}{$k_{s}$ in $\mu \mathrm{m}$} \\
\hline & & 30 & 300 & 1000 & 1475 & 3000 \\
\hline 1.94 & 3.264 & 0.62 & 1.91 & 2.83 & 3.39 & 3.40 \\
\hline 3.24 & 2.907 & 1.02 & 4.63 & 5.47 & 5.91 & 5.94 \\
\hline 4.86 & 2.670 & 1.23 & 5.47 & 7.79 & 8.02 & 8.36 \\
\hline 6.48 & 2.506 & 1.44 & 7.03 & 10.07 & 10.29 & 10.57 \\
\hline
\end{tabular}




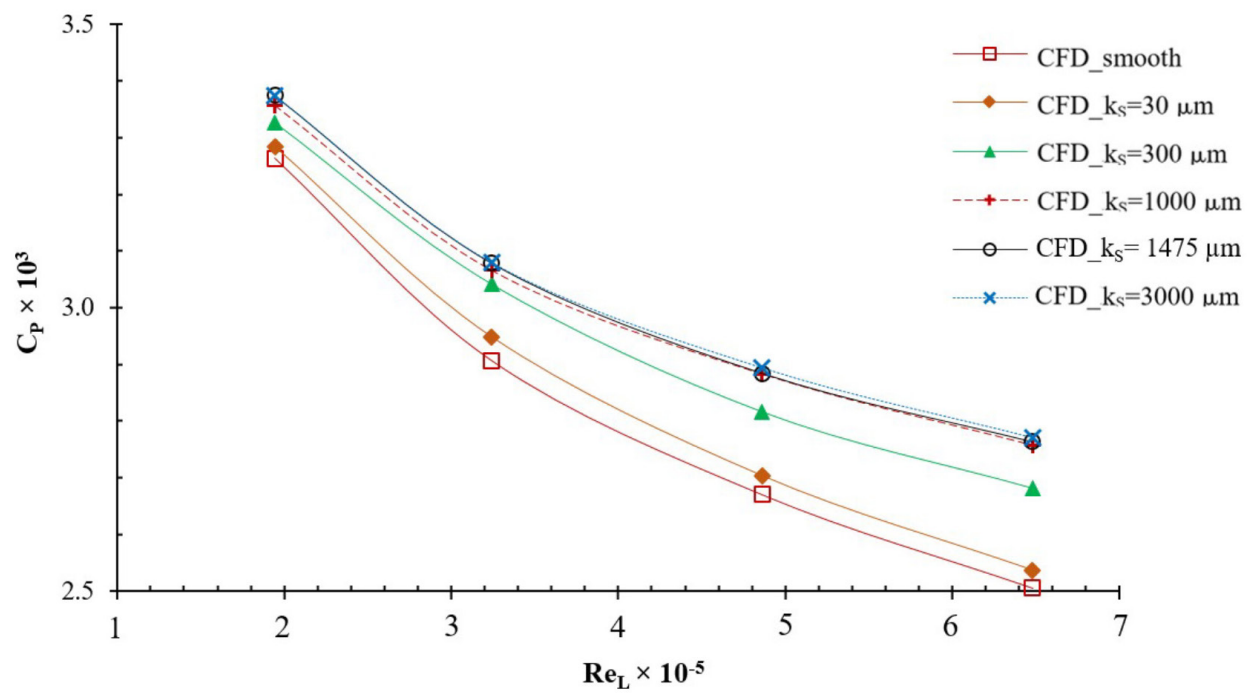

Figure 11: The $C P$ comparison for $C F D$ results against Reynolds number

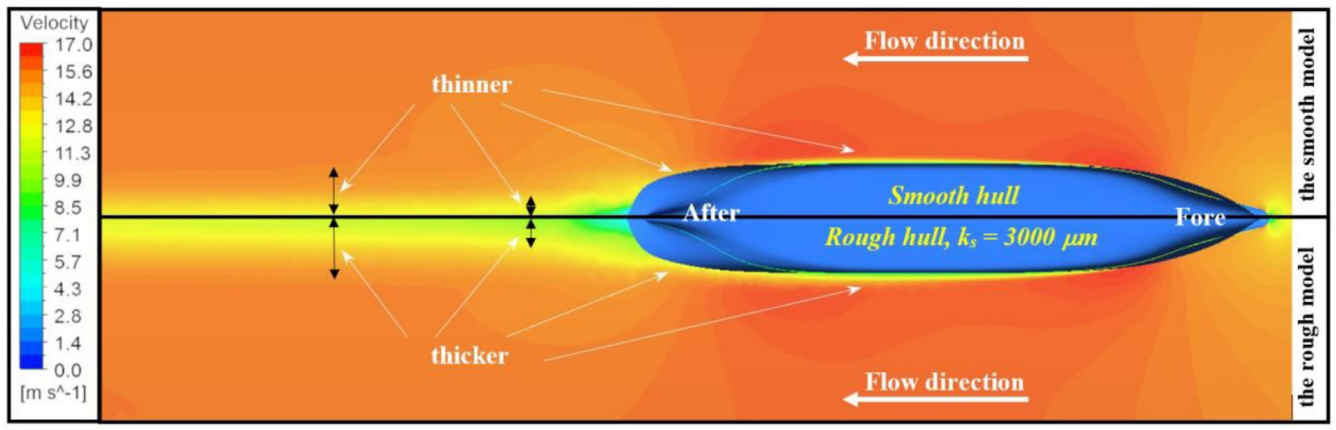

Figure 12: Velocity contour differences in smooth and rough models

Roughness Value Against the Resistance Components

This subsection explains the relationship between the roughness value $\left(k_{s}\right)$ and the results of resistance components, namely $C_{F}$ and $C_{P}$. Thus, it can be seen how the pattern of changing each resistance component due to increased roughness value.

The relationship between $k_{s}$ and $C_{F}$ was plotted in Figure 13a, where as the increase in $k_{s}$ then the $C_{F}$ continues to increase significantly. For example, in $\mathrm{Re}=1.94 \times 10^{5}$, where it started at $k_{s}=0 \mu \mathrm{m}$, the $C_{F}$ was at around $6.9 \times 10^{-3}$, then it continuously increased to $7.2 \times 10^{-3}$ for $k_{s}=30$ $\mu \mathrm{m}$ and then the $C_{F}$ was at $8 \times 10^{-3}$ for $k_{s}=300$ $\mu \mathrm{m}$, then it was at $149.5 \times 10^{-3}$ for $k_{s}=1000 \mu \mathrm{m}$,
$10.2 \times 10^{-3}$ for $k_{\mathrm{s}}=1475 \mu \mathrm{m}$, and finally, it was at $12 \times 10^{-3}$ for $k_{s}=3000 \mu \mathrm{m}$. From the drastically increasing curve, this shows that $k_{s}$ is greatly influenced the increase in friction resistance.

The relationship $k_{s}$ against $C P$ showed in Figure 13b. Based on the results, the increase in $C_{P}$ almost all occurred at $k_{s}$ from $0 \mathrm{~mm}$ to $30 \mathrm{~mm}$ then up to $1000 \mu \mathrm{m}$. The curves became slightly constant at $k_{s}=1000 \mu \mathrm{m}$ to $3000 \mu \mathrm{m}$, although in Table 5 there were slightly increased. For example in $\mathrm{Re}=1.94 \times 10^{5}$, where it started at $k_{s}$ $=0 \mu \mathrm{m}$, the $C_{P}$ was at around $3.26 \times 10^{-3}$, then it continuously raised at $3.28 \times 10^{-3}$ for $k_{s}=$ $30 \mu \mathrm{m}$ and then the $C_{F}$ was at $223.33 \times 10^{-3}$ for $k_{s}=300 \mu \mathrm{m}$, then it was at $3.36 \times 10^{-3}$ for $k_{s}$ $=1000 \mu \mathrm{m}$, it was at $3.37 \times 10^{-3}$ for $k_{s}=1475$ 

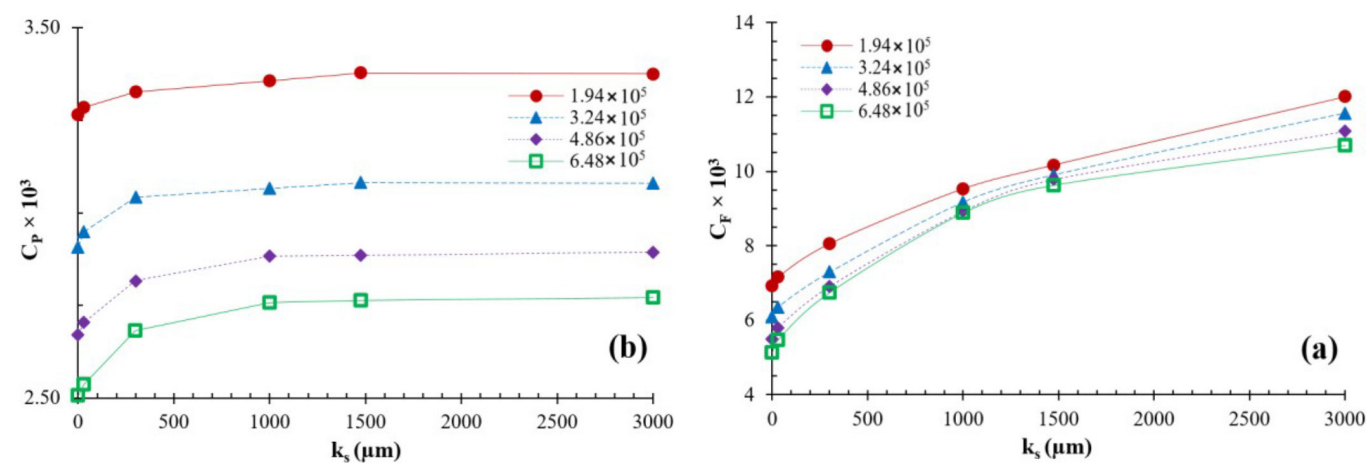

Figure 13: The effects increase the $k_{s}$ value to: (a) $C_{F}$, and (b) $C_{P}$

$\mu \mathrm{m}$, and finally, it was at $3.38 \times 10^{-3}$ for $k_{s}=3000$ $\mu \mathrm{m}$. From this curve, it shows that the increase in pressure resistance due to roughness was not as drastic as the increase in friction resistance.

\section{Conclusion}

Figure 13: The effects increase the $k_{s}$ value to: (a) $C_{F}$, and (b) $C_{P}$ Wind-tunnel experiments and CFD simulations were carried out for investigating the increasing resistances due to roughness in the ship hull models. Two models were prepared, one for the smooth-walled and another for the rough-walled. The roughness model used for the experiments was made from the grain of sandpaper with $k_{a}=162 \mathrm{~mm}$. While in the CFD simulations (RANS), the roughness was represented using $k_{s}$ where it used a roughness function $\left(\Delta U^{+}\right)$like the Nikuradse curve.

The experiments and the CFD simulations were run with four variants of freestream velocity. Variations of $k_{s}$ were also applied in the simulations.

The experimental results were obtained and had the highest uncertainty value of $\pm 11.17 \%$. The simulation results were also obtained by previously with grid sensitivity analysis, which had a value below $2 \%$. Then the simulation results were matched with the empirical calculations of ITTC 1957, where the difference was below $1 \%$. Then the results of experiments and the simulations were ready to be analyzed.
The curve matching with non-linear regression method based on the CFD data was carried out to predict the $k_{s}$ value from the experimental roughness model (made from sandpaper with $k_{a}=162 \mu \mathrm{m}$ ). The result indicated that the $k_{a}=162 \mu \mathrm{m}$ was equal with $k_{a}=1475 \mu \mathrm{m}$. This results also explains that $k_{a}$ cannot be used to predict an increase in friction resistance due to roughness as $k_{s}$.

Based on the results, the increase in total resistance due to roughness was quite high, which could reach $73.70 \%$ for $k_{s}=3000 \mu \mathrm{m}$ and $\operatorname{Re}=\operatorname{Re}=6.48 \times 10^{5}$. This situation will be very detrimental to many parties, related to the emissions (environment) and the economy (fuel consumption).

For the components of resistance (friction and pressure), based on the results, there were differences. The increase in friction resistance due to roughness occurred an extreme increase, where it could reach $106.96 \%$ for $k_{s}=3000 \mu \mathrm{m}$ and $\operatorname{Re}=6.48 \times 10^{5}$. While for the increase in pressure resistance occurred not drastic, where the highest reached only $10.57 \%$ for $k_{s}=3000$ $\mu \mathrm{m}$ and $\operatorname{Re}=6.48 \times 10^{5}$.

The increase in ship resistance component due to roughness needs to be predicted in more detail, including the addition of wave resistance calculations. Because based on these results, it is believed that there are other parameters that can affect the value in more detail. For example, such as the hull shape, the hull configuration, the hull interaction with appendages (rudder, 
propeller, fins, skeg). Then, the determination of the value of $k_{\mathrm{s}}$ for a certain roughness that is not easy to obtain, and perhaps most industrial simulations enter $k_{a}$ as $k_{s}$, and were based on these simulation results, the results would differ greatly. The hope, with more detailed prediction calculations, will increase the enthusiasm to fight energy waste due to biofouling that is more real to encourage the creation of an environmentally friendly fleet.

\section{Acknowledgements}

This research project was funded by the Ministry of Research, Technology, and National Innovation and Research Agency (Kemenristek - BRIN) of the Republic of Indonesia under a program called "Master to Doctor Program for Excellent Graduate (PMDSU) Batch III with Grant Number: 1277/PKS/ITS/2020.

\section{References}

Anderson, J. (1995). Computational fluid dynamics: The basics with applications. New York: McGraw-Hill Inc.

Atencio, B. N., \& Chemoray, V. (2019). A resolved RANS CFD approach for drag characterization of antifouling paints. Ocean Engineering, 171, 519-532.

Cebeci, T., \& Bradshaw, P. (1977). Momentum transfer in boundary layers. New York: Hemisphere Publishing Corporation.

Celik, I. B., Ghia, U., Roache, P. J., Freitas, C. J., Coleman, H., \& Raad, P. E. (2008). Procedure for estimation and reporting of uncertainty due to discretization in CFD applications, J. Fluids Eng. Trans. ASME, 130, 078001-1-4.

Demirel, Y. K., Khorasanchi, M., Turan, O., \& Incecik, A. (2004). A CFD model for the frictional resistance prediction of antifouling coatings. Ocean Engineering, 89, 21-31.

Demirel. Y. K., Turan, O., \& Incecik, A. (2017). Predicting the effect of biofouling on ship resistance using CFD. Applied Ocean Research, 62, 100-118.

Fergizer, J., \& Peric, M. (2010). Computational methods for fluid dynamics (3rd ed.). Springer.

Granville, P. S. (1958). The frictional resistance and turbulent boundary layer of rough surfaces. J. Ship Res, 2, 52-74.

Granville, P. S. (1978). Similarity-law characterization methods for arbitrary hydrodynamic roughnesses. Final Report Naval Ship Research and Development Center, Ship Performance Dept., Bethesda, $M D$, pp. 1.

Habibi, M. T. (2017). Desain Prototip drag and lift balance pada wind tunnel siklus tertutup. [Undergraduate Theses, Department of Mechanical Engineering, Institut Teknologi Sepuluh Nopember].

Hakim, M. L, Nugroho, B., Chin, C., Putranto, T., Suastika, I., \& Utama, I. (2018). Assessment of drag penalty resulting from the roughness of freshly cleaned and painted ship hull using Computational Fluid Dynamics. Proceeding of 11th International Conference on Marine Technology (MARTEC), Kuala Lumpur, Malaysia.

Hakim, M. L., Nugroho, B., Nurrohman, M. N., Suastika, I. K., \& Utama, I. K. A. P. (2019). Investigation of fuel consumption on an operating ship due to biofouling growth and quality of anti-fouling coating. IOP Conf. Series: Earth and Environmental Sci. doi: 10.1088/1755-1315/339/1/012037.

Hakim, M. L, Nugroho, B., Chin, C., Putranto, T., Suastika, I., \& Utama, I. (2020). Drag Penalty Causing from the Roughness of Recently Cleaned and Painted Ship Hull Using RANS CFD. CFD Letters, 12,(3), 78-88. doi: 10.37934/cfdl.12.3.7888

IMO. (2001). International Convention on the Control of Harmful Anti-fouling Systems on Ships (AFS). IMO Conventions. 
IMO. (2009). Second IMO GHG Study 2009. http://www.imo.org/en/OurWork/ Environment/PollutionPrevention/ AirPollution/Documents/SecondIMO GHGStudy2009.pdf

IMO. (2012). Resolution MEPC.213(63). Guidelines for the development of a Ship Energy Efficiency Management Plan (SEEMP).

IMO. (2014). Resolution MEPC. 245(66). Guidelines on the method of calculation of the attained Energy Efficiency Design Index (EEDI) for new ships.

IMO. (2015). Third IMO GHG Study 2014. http://www.imo.org/en/OurWork/ Environment/PollutionPrevention/ AirPollution/Documents/Third\%20 Greenhouse $\% 20$ Gas\%20Study/GHG3\%20 Executive \%20Summary $\% 20$ and $\% 20$ Report.pdf

ISO 6344-2. (1998). Determination of grain size distribution of macro grits P12 to P220.

ITTC. (2008). Report of the Specialist Committee on Powering Performance Prediction, Proceedings of the 25th International Towing Tank Conference, Vol. 2, Fukuoka, Japan.

ITTC. (2011). Specialist Committee on Surface Treatment-Final report and recommendations to the 26th ITTC. Proceedings of 26th I T T C , Vol II. Retrieved from http://ittcinfo/ media/5532/11.pdf.

Kodama, Y., Kakugawa, A., Takahashi, T., \& Kawashima, H. (2000). Experimental study on microbubbles and their applicability to ships for skin friction reduction. Int. J. Heat and Fluid Flow, 21, 582-588.

Menter, F. R. (1994). Two-equation eddyviscosity turbulence models for engineering applications. AIAA Journal, 32(8), 15981605.

Molland, A. F., Turnock, S., \& Hudson, D. (2017). Ship resistance and propulsion $\left(2^{\mathrm{nd}}\right.$ ed.) Cambridge: Cambridge university press.

Molland, A. F., Turnock, S., Hudson, D., \& Utama, I. (2014). Reducing ship emissions: A review of potential practical improvements in the propulsive efficiency of future. Transaction RINA: IJME, 156(A2), 175-188.

Monty, J. P., Dogan, E., Hanson, R., Scardino, A. J., Ganapathisubramani, B., \& Hutchins, N. (2016). An assessment of the ship drag penalty arising from light calcareous tubeworm fouling. Biofouling, 32(4), 451464.

Nikuradse, J. (1933). Laws of flow in rough pipes. NACA Technical Memorandum 1292. RAEng. (2013). Future Ship Powering Options. https://www.raeng. org.uk/publications/reports/future-shippowering-options

Rompay, B. V. (2012). Surface treated composites white book (clearwater). FL: Tahoka Press.

Song, S., Demirel, Y. K., \& Atlar, M. (2019). An investigation into the effect of biofouling on the ship hydrodynamic characteristics using CFD. Ocean Engineering, 175, 122137.

Schultz, M. P. (2007). Effects of coating roughness and biofouling on ship resistance and powering. Biofouling, 23, 331-341.

Schultz, M. P., \& Flack, K. (2007). The roughwall turbulent boundary layer from the hydraulically smooth to the fully rough regime, J. Fluid Mech, 580, 381-405.

Schultz, M. P., Bendick, J. A., Holm, E. R., \& Hertel, W. M. (2011). Economic impact of biofouling on a naval surface ship. Biofouling, 27, 87-89.

Townsin, R. L. (2003). The ship hull fouling penalty. Biofouling, 19, 9-15.

Utama, I., Nugroho, B., Chin, C., Hakim, M. L., Prasetyo, F. A., Yusuf, M., \& 
Ganapathisubramani, B. (2017). A study of skin friction drag from realistic roughness of a freshly cleaned and painted ship hull. Proceeding of International Symposium on Marine Engineering (ISME), Tokyo.

Utama, I., \& Nugroho, B. (2018). Biofouling, ship drag, and fuel consumption: A brief overview. The Journal of Ocean Technology, 3(2), 43-48.

Utama, I., Nugroho, B., Monty, J., Hutchins, N., \& Ganapathisubramani, B. (2018).
Recent progress in estimating ship-hull drag penalty. Proceeding of the 1st Maritime Safety International Conference (MASTIC), Bali, Indonesia.

Wang, H., \& Lutsey, N. (2013). International Council on Clean Transportation (ICCT). Long-Term Potential for Increased Shipping Efficiency Through the Adoption of Industry-Leading Practices. 